\title{
IMPACT OF BUYING BEHAVIORS OF YOUNG CUSTOMERS ON SOCIAL MEDIA ADVERTISEMENTS
}

\author{
PRAVEEN .N .A ${ }^{1}$ \\ Assistant Professor. Dept. of Commerce. \\ RTES Arts, Science \& Commerce Degree College, Ranebennur - 581115, Haveri (District), \\ Karnataka (State). INDIA. \\ Mobile No: 9686419341. \\ E-mail Id : Praveenna8@gmail.com.
}

\begin{abstract}
The Internet today has been hailed as the single most important invention of the $20^{\text {th }}$ Century. with its increasing popularity as noticed from a greater number of users coming 'online' and more services being offered 'online' in general the internet now occupies a central role in young educated people's lives, all over India. with its burgeoning population and rapidly increasing Net penetration, India has caught on to the fancy of Internet marketers or.com companies. Marketers today realize the favorable conditions in terms of the huge size of the young population, increasing literacy rate, growing internet penetration and a fast-track economy. They are ready to exploit the opportunity to reap huge gains and rewards. Marketers also realize that young consumers are becoming increasingly technology savvy and are logging -on now more than ever for purchase of personal necessities besides booking an airline or a railway ticket and the famed information search. Consumers in India spend approximately 6 times as much time on information search online as they do offline. Marketers have been quick to hook on to this opportunity by developing marketing strategies to leverage the increased Internet usage. Their strategies include web banners (Pop ups), search engine marketing, email marketing, and interactive web -based marketing. Internet marketing also helps marketers segment consumers into specific consumer groups based on their visits to specific sites, use of specific services, browsing sites, downloading specific content, and so on etc.,...
\end{abstract}

KEY WORDS: Consumer buying behavior, MNC's, Search Engine Optimization (SEO), Social Influencers, Social media savvy. 


\section{INTRODUCTION}

All of us are consumers. We consume things of daily use, we also consume and buy these products according to our needs, preferences and buying power. These can be consumable goods, durable goods, specialty goods or, industrial goods.

What we buy, how we buy, where and when we buy, in how much quantity we buy depends on our perception, self-concept, social and cultural background and our age and family cycle, our attitudes, beliefs values, motivation, personality, social class and many other factors that are both internal and external to us. While buying, we also consider whether to buy or not to buy and, from which source or seller to buy. In some societies there is a lot of affluence and these societies can afford to buy in greater quantities and at shorter intervals. In poor societies, the consumer can barely meet his barest needs.

Consumer buying behavior is the study of how individuals and organizations select and use products and services. This primarily focuses on psychology, motivations, and behaviors, such as how people choose between brands, how they research and shop, and how marketing campaigns can be improved so brands can effectively influence them.

Three factors can influence consumer buying behavior: personal, psychological, and social. Personal factors deal with an individual's interests and opinions, which are affected by their demographics. Psychological factors are based on their perceptions and attitudes, including their ability to comprehend information and how they see their needs. Finally, social factors are made up of one's peer groups, socioeconomic classes, and even social media influence.

While each person has their own considerations for making purchases, everyone goes through what is known as the buying process. This process is constant, with consumers sitting at a particular stage at any given time.

\section{DIVERSITY OF THE INDIAN MARKET.}

India with a population of more than a billion presents a tremendous market opportunity. With rising income levels, increasing disposable income, and propensity to consume, the Indian market has seen the entry of leading MNC's. However, it has simultaneously posed many challenges to the marketers to understand the behavior of the Indian consumers. Here consumers are noted for ahigh degree of value consciousness. Such value consciousness has labelled Indians as "one of the most discerning consumers in the world". Even luxury brands have to offer specific distinct values to justify its premium pricing in order to get a foothold in the Indian market. In general, Indian consumers have shown a high degree of family orientation. That's why probably brands that support family values tend to be popular and are accepted easily.

Indian consumers are also associated with the values of nurturing, care, love and affection. These values are far more dominant then values of ambition and achievement. Products which communicate traditions and emotions could tune better with the Indian consumers. Apart from 
psychology and economics, past habit and traditions also influence the Indian consumer behavior. Perhaps, only in India one finds traditional products alongside modern products. That's why, hair oils and tooth powder (mainly Ayurveda) co-exist with shampoos and toothpaste.

The Indian market, one of the most promising in the world is fast evolving. So is the Indian consumer across all socioeconomic strata, regions and town classes. Rising incomes, multiple income households, exposure to international lifestyles and media, easier financial credit and an upbeat economy are enhancing aspirations and consumption. While the consumer goods industry in India is growing horizontally, the configuration of consumer profile is also changing rapidly. The affordability is increasing and the size of low-income segment is shrinking, whereas the middle-income class is growing. In these fast-changing times, it becomes imperative for companies that they reach out to the Indian market so as to feel the pulse of the Indian consumer.

\section{STAGES IN THE BUYING PROCESS.}

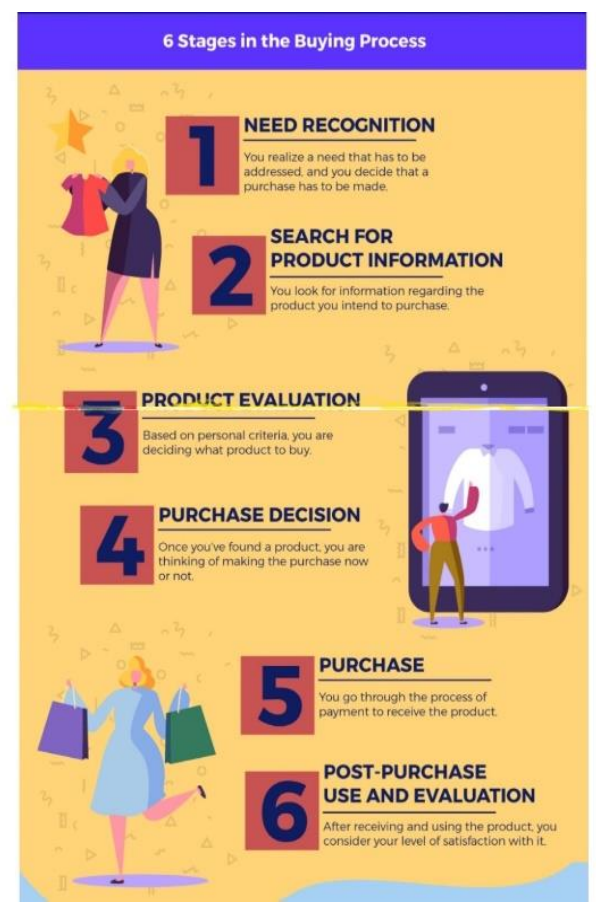

\subsection{Need Recognition.}

This stage is where the consumers realize that they need something and that making a purchase will address the need. It can range from wearing out a sahirt and needing a replacement to seeing a movie trailer, wanting to buy a ticket, and watching it out of curiosity or interest.

For businesses, this is an opportunity to use other marketing strategies to help prospects recognize a need or reevaluate an existing one. 


\subsection{Search for Product Information.}

At this stage, your prospects are looking for more information about the product they want to purchase. This is where product reviews, websites, blog posts, and search ads can come in handy. Establishing your brand's credibility in the induastry, like through paid ads and Search Engine Optimization (SEO), can help convert your prospects into making their purchase with you.

\subsection{Product Evaluation.}

Given that many different products could address their needs, consumers often use evaluative criteria based on their priorities. To help narrow down their choices, they also consider their needs. At this stage, your marketing strategies should be aiming to convince prospects that their criteria match your product's strengths.

\subsection{Purchase Decision.}

The consumer has looked at multiple items and compared them based on their evaluative criteria. They are now at the cusp of the critical decision: to make the purchase or not. Businesses need to focus on creating a sense of security and give compelling reminders of their needs.

\subsection{Purchase.}

This is the stage where the consumer has decided to make the purchase. However, it's still possible to lose a prospect due to things like complicated checkout processes, difficult-to-navigate ecommerce sites, and unresponsive or malfunctioning elements. Keeping the process convenient and streamlined can spell the difference between a closed or lost sale.

\subsection{Post-purchase use and evaluation.}

The Buying Process doesn't end at the sale. Your customer's experience with the product would dictate if they were satisfied by the purchase or not. Post-purchase surveys and thank-you emails to your customers can significantly help address any issues that may arise from dissatisfaction while cultivating a relationship with those who felt satisfied.

\section{SOCIAL MEDIA FACTORS THAT INFLUENCE CONSUMER BUYING BEHAVIOR.}

Social media can play a huge role in influencing consumers in their purchases. Here are some of the ways that social media affects the behaviors of your target market.

\subsection{Reviews from influencers.}

The term "social influencers" refers to individuals with a significant following on social media. Influencers are social media-savvy and often tag the store or brand of the 
products they are using, giving these institutions a broad reach over specific demographics. Regardless if their posts are sponsored or not, their followers can be swayed in either picking up or passing on a purchase.

\subsection{Reviews from social media connections.}

Social media's initial purpose was to connect people and allow them to share information. Now, social media can be a powerful tool for users to voice their opinion on a product or brand with faster speed and broader reach. With $81 \%$ of consumers considering purchases based on a friend's suggestions, there's no denying the influence it has on your target market.

\subsection{Brand's social media presence.}

It's not enough to be selling products and services online. Your brand must stand out and be recognizable amidst the sea of information available to social media users. Having a consistent and distinct voice on your chosen social media platform-plus a regularly updated feed — can boost your brand image and credibility to your existing followers and prospects, making conversions more likely to happen.

\subsection{Social media advertising.}

As social media continuously reaches a wider audience, social media advertising has made it possible for hyper focused targeting and retargeting. This allows brands to make more strategic marketing strategies that reach their market while maximizing their resources.

\section{5 "Trending" and "Popular" algorithms.}

Platforms like Facebook and Instagram have moved from showing posts on their newsfeeds chronologically to displaying posts with more engagements first. Brands and businesses can take advantage of this algorithm by encouraging likes, comments, and shares on their content. This move can also foster conversations between companies and consumers, and influence overall brand image.

\section{REVIEW OF LITERATURE.}

\subsection{Social Media.}

Forbes, (2017) in today's borderless world, people throughout the globe are using social media in real time for various purposes of communication, with majority spending almost a quarter of their daily time, surfing social networks.

Dehghani and Tumer (2015) find that Facebook advertising can significantly affect the brand image and equity by offering greater interactivity, personalization and feedback. This process can in turn, affect consumer purchase intensions. 
Pjero and Kercini (2015) in their study focusing on social media and its influence on consumer behavior observe that information about products and services offered in the virtual world can positively impact the purchase intensions of consumers.

Magneto (2015) reported that a few years back, the concept of consumer engagement was about catching the attention of consumers by emphasizing on 'touch-points' when marketing products and services. Presently, with a vast range of merchandise options, media means and novel shopping experiences, consumer engagement is about making supreme efforts and constructing emotional ties which can steer the word of mouth marketing and generate future sales.

\subsection{Social Media Marketing.}

Forbes (2015) reported that today's companies need to utilize the influence of social media to engage consumers instead of using it only as a platform for intensifying their products and brand promotions. Social media can be used to engage consumers by creating value for them. In other words, strengthening social network marketing as a medium for business promotion is necessary.

Mirabi, Akbariyeh, and Tahmasebifard (2015), reported that factors such as product quality, brand and advertisement can be most important factors that contribute to consumer's purchase intention. These factors act as the very reason for companies to invest more on the marketing efforts achieved through novel means besides traditional approaches as both approaches can help to boost their market shares.

Ali, Ejaz, Aleem, Saeed, and Tahir, (2015) said that, web marketing help consumer to be updated and get their product on time with safely. This kind of consumer's attitude affects the businessmen also. Their techniques and ideas changes regarding e-marketing and other websites regarding online marketing as well. Though the study we analyse that e-marketing relay on 4 dimensions, that is e-mail marketing, web marketing, e-marketing and internet marketing as well.

Bakshi and Dr. Surender Kumar Gupta, (2015) said, it over take television, radio and newspaper advertisement. According to different business journals of America, internet advertisement is quicker than traditional one. With dramatic increase in online advertisement company started to do or spend more on e-marketing rather than traditional one.

Yasmin, Tasneem, and Fatema, (2015) reported that developing countries have less impact on online marketing and selling activities. They still trust or believe on those old traditional marketing methods. Nowadays in digital era consumers are greatly affecting traditional marketing then digital marketing.

\subsection{Online Marketing.}

K and M, (2015) reported that online buying and selling are dramatically increase, because in this fast-moving research on goods and services consumers don't relay easily on any product before they completely research on it. Digital marketing is the future of globalization and online marketing industry. Study showed that online word of mouth has greatly affecting on consumer 
purchase behavior and decision. Study also showed that $70 \%$ of the US population trust online shopping by experiencing them personally, through dealing with different buyers, sellers and other legally online shopping websites.

Ngai, Taoa, and Moon, (2015) in the context of this study, the application of the UGT is based on the assumption that the consumer is an active and self-conscious contributor in media choice; the consumer is also driven by personal goals rather than the influence of the media. This theory thus assumes the position that the consumers will seek out the media that fulfils their needs and so their gratification. Consequently, it is the consumer's gratification that would lead to the recurring media use. Thus, the media choice of the consumer is considered to be objective-oriented and value focused.

Krishnamurthy and Sin, (2014) digital marketing cybernetic societies have changed consumer, society and corporate sector to information, social networking and educational sector. Social networking sites have huge target market and audience. Huge number of spectators and users throughout the world. They mostly get information of product and services that have been marketed online through Facebook, YouTube videos, and other social networking sites.

Elisabeta Ioanas, (2014) studied that online marketing can be done by different online tools like digital marketing, Mobile marketing, Social networking sites, Web marketing and E-mails.

Chukwu and Uzoma (2014) provided scientific evidences to show that Nigerian consumer patronize online retailers very significantly. One wonders what is responsible for the noted changes.

\subsection{Customer Perception for Online Marketing through Social Media.}

Hussain and Adamu (2014) Online marketing use all facets of internet advertising to generate response from the prospected customers and owing to the wide use of internet in all dimensions of life, the procurement in the first world countries mainly has been enhanced and now spreading to other countries rapidly. One theme that has often received wide attention among researchers is the factors that influence consumes to shop online. This helps in determining the success of emerging online shopping habits of new breed of consumers.

Hidayat and Diwasasri, (2013) reported that consumer purchase intention has been used as a key construct in marketing researches in a variety of contexts but they include varying variables such as consumer attitudes perceived value perceived risks, usefulness and the ease of use.

According to Nielsen's study (2013) consumers spend more time on social networks than on any other category of website. Approximately 20 percent of their total time online was used on a personal computer (PC) and 30 percent of total time online on a mobile device. Other devices such as tablets, game consoles, handheld music players and e-readers also increased in popularity for accessing social media.

Laudon and Traver (2013) the Internet has succeeded in expanding the information intensity of the market place immensely by providing marketers and customers with well detailed realtime information about consumers as they transact in the market. Consumers are much more 
available to receive marketing messages due to the "always-on" environment created by mobile devices which results to an extraordinary increase in marketing opportunities for firms.

Gangeshwer, (2013) as we living in $21^{\text {st }}$ Century, people have less time and more work to do that they planned up. So, for those busy people internet marketing is a huge benefit, they feel more comfortable with that. It cut down their travelling cost and other expenses.

Ngamkroeckjoti, Lou and Kijboonchoo, (2011) in their study identified the influences of attitude, prestige and purchase intension of both genders. In addition, the casual relationship among prestige, attitude, and purchase intension was also confirmed.

Wan Chik, (2006) study indicated that the product customization mechanism does affect online consumer's shopping enjoyment, which then leads to the intension to purchase Batik fabric online.

Miles et al., (2000) as in the case of traditional marketing in the past, most of the recent research and debate is focused on the identification and analysis of factors that one way or another can influence or even shape the online consumer's behavior; a good deal of research effort is focused on modelling the online buying and Decision-making process.

\section{HOW DOES SOCIAL MEDIA INFLUENCE CONSUMER BUYING BEHAVIOR?}

Social media has occupied an important position as a communication tool. People across the globe use social media to connect to other people or organizations.

Globally, people have started to use social media such as Facebook, YouTube, Twitter, Instagram and LinkedIn to share their experiences. As customers, people share product reviews, information about a service, advice on food or health, warnings about products, tips on using certain products, and much more. People have a lot of 'connections' on social media, therefore information is consumed by many people. This information becomes a source of influence on consumers and their buying behavior. Research studies have shown that many people rely on the information and reviews on social media as a guide for planning their future purchases.

Social media has grown in terms of its reach and impact. Here is a statistic to prove that.

$54 \%$ of social browsers use social media to research products (GlobalWebIndex, 2018).

\subsection{Four Ways Social Media Influences on Consumer Buying Behavior.}

More buyers are now on social media networks than ever before. Consumers are looking for reviews and recommendations. Therefore, it's essential to have a prominent online presence on various social media platforms. The latest trend in marketing is the introduction of the social media. Social media has the power to influence potential customers from the start until the stage of a purchase and beyond as well. To start off, consumers need awareness about your brand and its offering. At a later stage, when they start to narrow down their choices, you need a social media influencer to convince their choice. A constant dialogue between the customer 
and the brand is essential to keep the relationship strong. Attractive and informative content can glue the customers to your brand.

Here are 4 ways in which social media influences consumer behavior:

1) Builds product awareness.

Social media is a huge influence on consumers when they are attempting to build awareness about a particular product. When people face a problem, they start searching for a solution. But most of the times people do not know which product or service will solve their problems.

How do people get to know about your product? A large section of the audience gets to know your brand through the content that is distributed on social media.

\section{2) Social proof as a greater force of buying decisions.}

Social media has resulted in the evolution of social proof as a greater force for buying decisions. Social proof has emerged due to the tendency of people to imitate the behavior of people around them or people imitate people who have influence over them. Happy customers tend to go about praising the products with likes, shares, reviews and comments on social media. Marketers are making social space more transparent by sharing reviews, comments, likes, tweets and pins of their happy customers to generate brand trust and increase conversion rate. Sharing testimonials, case studies, pictures, comments and videos of happy customers will build greater trust and will work well on your landing, page, consulting page and sign-up page as well. The power of social proof cannot be undermined when social media has become integral part of buyers and sellers. Social marketers looking to sell their products should have a solid social proof in form of case studies, images, video, pod cast interviews and influencers as part of their selling strategy. All this will eventually increase the conversion rate.

\section{3) Promotions, Discounts and deals on Social Media.}

Many social media users have signed up for social media groups/forums that they are interested in. When consumers see promotions, discounts and deals on social media, it influences their buying behavior. $64 \%$ of online consumers wait to buy things until they go for sale. Social media is an inexpensive platform that gives brands instant reach to billions of active social media users. Brands should ensure that target audience sees your products, likes them and shares them on social media, which helps to influence consumer behavior.

\section{4) Social Media Influencers.}

Consumers are more likely to buy when they get recommendations from a person they trust. Celebrities and popular people inspire their audience and influence their buying behavior. It is true that $49 \%$ of consumers seek guidance from social media influencers before making a buying decision.

For example, an influential gamer would endorse gaming and tech products. Consumers on social media look up to these influencers for recommendations and advice on products. A positive influence will encourage the consumer to buy the product. Influencer marketing can work wonders for your brand by attracting more customers. 
Many marketers are replacing celebrities with YouTube, Instagram, and Snapchat influencers. These online stars are providing unfiltered feedback on products, and consumers love it.

\section{CONCLUSION.}

Understanding consumer buying behavior has become a critical factor for any organization that strives to achieve a sustainable competitive advantage. However, the changing environment, the trend towards globalization, the emergence of new technology, consumer's preferences for local and global products, and changing consumer needs have made it a very complex task. An overview of consumer buying behavior, focusing on key stages that a consumer goes through when making a purchase decision. The stages in buying process factors are influencing consumer buying decisions and the new products adaptation. Overall, it is vitally important to understand consumers buying behavior in order to meet their expectations and gain competitive advantage.

The consumer benefit through these activities as their information search becomes simplified because of the marketer's effort. Also, Internet marketing helps marketers create database for existing consumers and return more relevant information searchers the next time they use the service, further simplifying the search process. India being a late entrant into the world of ecommerce, the consumers currently use the Internet mainly for information search with transactions being restricted to specific industries. However, with increasing awareness of ease of transactions and marketing strategies being designed to generate pull demand, e-commerce is touted to take off in a big way among the Indian consumers in the days to come.

\section{BIBLIOGRAPHY}

I . M. Khan. (2007). Consumer Behavior: New Age International Publications Ltd.

II . Ramanuj Majumdar. (2010). Consumer Behavior Insights from Indian Market: PHI Learning Publishers.

III. Shashank Tripathi, Archana Rai. (2019). Consumer Behavior on Social Media Marketing: Walnut Publications.

IV. Dan Zarrella. (2010). The Social Media Marketing Book: O’Reilly Media Publications.

V . Ayantunji .G. Badamosi, Ian .K. Bathgate, Sonny Nwankwo. (2013). Principles of Marketing A Value-Based Approach

: Palgrave Macmillan Publications.

VI. Robert .W. Palmatier, V. Kumar \& Colleen .M. Harmeling. (2017). Customer Engagement Marketing: Springer

International Publishing. 
VII. Nripendra .P. Rana, Emmal Slade, et. al. (2019). Digital \& Social Media Marketing: Springer International Publishing.

VIII. Sarmistha Sarma. (2017). Global Observations of the Influence of Culture on Consumer Buying Behavior: IGI Global

Publications.

X. https://connextdigital.com/how-social-media-impact-consumer-buying-behavior/.

X. https://connextdigital.com/social-media-advertising/.

XI. https://connextdigital.com/inapp-advertising/.

XII. https://clootrack.com/knowledge base/how-does-social-media-influence-consumer-behavior/. 